\title{
Availability of anticancer medicines in public and private sectors, and their affordability by low, middle and high- income class patients in Pakistan
}

\author{
Muhammad Rehan Sarwar ${ }^{1,2^{*}}$, Sadia Iftikhar ${ }^{2}$ and Anum Saqib ${ }^{1}$
}

\begin{abstract}
Background: Availability and affordability of anticancer medicines is a matter of great concern especially for low and middle income countries e.g., Pakistan. Prime focus of this study was to evaluate the availability of anticancer medicines in public and private sectors, and their affordability among patients with different income levels.

Methods: A descriptive, cross-sectional survey was conducted in 22 cancer care hospitals (18 public hospitals and 04 private hospitals) and 44 private pharmacies in Punjab, Pakistan. All $(n=4400)$ participants were $\geq 18$ years of age. Data were collected at different intervals and analyzed by using Statistical Packages for Social Sciences (IBM SPSS Statistics for Windows, Version 21.0. Armonk, NY: IBM Corp.)

Results: A total of 4913 patients were approached, and 4400 responded to the survey (response rate $=89.6 \%$ ). Non-hodgkin lymphoma (12.3\%), breast cancer (8.6\%), and leukemia (7.6\%) were the most prevailing cancers. Conventional medicines like cisplatin, cyclophosphamide, and etoposide were the most prescribed medicines. Oncologists were reluctant to prescribe newer anticancer medicines due to high prices. Originator brands (OBs) were more readily available (52.5\%) but less affordable (53.4\%); whereas, lowest price generics (LPGs) were less available (28.1\%) but more affordable (67.9\%). Anticancer medicines were more affordable by the high income class patients than the low income class patients.

Conclusion: The availability of both OBs and LPGs was greater at private hospitals and pharmacies as compared to public hospitals. The high income class had more affordability of both OBs and LPGs; however, LPGs were more affordable for all income classes.
\end{abstract}

Keywords: Cancer, Anticancer medicines, Availability, Affordability, Originator brand, Lowest price generics

\section{Background}

Cancer is amongst the most expensive and lethal noncommunicable diseases globally [1]. In 2016, the most prevailing cancers in Pakistan were breast cancer (21.8\%), leukemia (6.3\%), hodgkin lymphomas (4.9\%) and non-hodgkin lymphoma $(4.7 \%)$ of the total reported cases [2]. However, the actual prevalence of cancer may be greater than this due to lack of availability of proper registry system in Pakistan. Presently, the management

\footnotetext{
* Correspondence: rehansarwaralvi@gmail.com

${ }^{1}$ Department of Pharmacy, The Islamia University of Bahawalpur, Bahawalpur, Punjab, Pakistan

${ }^{2}$ Akhtar Saeed College of Pharmaceutical Sciences, Lahore, Pakistan
}

of cancer mainly relies upon the availability and affordability of anticancer medicines. In recent years, the emergence of newer anticancer medicines has rapidly and substantially caused an expansion not only in the repertoire but also in the average per month cost of these therapeutic agents. Cancer treatment demands substantial cost i.e., ranging from $\$ 4500$ to $>\$ 10,000$ per month $[3,4]$, thus posing huge burden on patient and healthcare system.

The heath sector of Pakistan is regulated by the provincial governments. The government health coverage is inadequate and negligible in terms of public health insurance and employer benefits. Therefore, majority of 
the population have to bear their health expenses on their own [5]. In 2004, a "National Action Plan for Prevention and Control of Non-Communicable Diseases and Health Promotion" [6] was developed with the collaboration of World Health Organization (WHO). This plan was designed to cover various aspects e.g., capacity enhancement of healthcare system, up-gradation of cancer registration, and making an organizational network at local, provincial and national levels. For accomplishing all such goals the WHO cancer coordinator for Pakistan has also developed a National Cancer Control Council. Because of financial constraints the government of Pakistan was unable to contribute in this program and all strategies were merely dependent on the funding from the WHO [7].

Several factors which affect the accessibility of any therapeutic agent have an impact on patient's pocket and subsequently cause a considerable delay in the commencement of therapy [8]. Some of these factors may include (a) the extent to which a drug is reimbursed or subsidized, (b) the allocation of budget by the public sector for the purchase of medicines, (c) licensing of medicines for manufacturing and import, (d) implication of evidence-based guidelines, and (e) procurement by the government hospitals and insurers [9]. The need of pre-approval for the provision of subsidized medicines and "mark-up values" by the hospitals, wholesale dealers, pharmacists, and physicians may also contribute in making the prices extremely high $[10,11]$.

Pricing of medicines in Pakistan are regulated by the Drug Regulatory Authority of Pakistan (DRAP) which works under Federal government, though no transparent price calculation formula is mentioned in the Drugs Act, 1976 [12]. According to a survey conducted by the WHO, the prices of originator brands (OBs) and lowestprice generics (LPGs) were 3.36 and 2.26 times more than the international retail price in Pakistan. Moreover, a sudden rise in price of 15\% in November 2013 further burdened the patients [13].

The affordability of anticancer medicines is a grave problem for most of the Pakistani patients. Since 45.5\% of the Pakistani population lives below the poverty line [14] so the expenses pertaining to healthcare are unaffordable for an average income person. The availability and affordability of anticancer medicines in Pakistan are surrounded by evidence based three common issues which include: (i) formulary limitations; anticancer medicines have not been mapped in the form of formulary, (ii) actual availability; inadequate provision of health services due to shortage or poor availability of medicines $[13,15]$ and (iii) the barriers like resources and affordability associated with the access of newer anticancer medicines. Moreover, inflation (Consumer Price Index (CPI) inflation: $1.3 \%$ on year-on-year basis in September
2015) and low affordability leads to an underuse of effective medicines. Despite of several measures adopted by the Ministry of National Health Services, regulations and coordination of affordability of medicines is still a problem owing to the expansion of OBs, and ongoing variation and inconsistency of prices of medicines in the country. The availability of essential generic medicines is only $15 \%$ and $31 \%$ in the public and private sector healthcare facilities, respectively. Even though the LPGs are used but still the cost of treatment for chronic illnesses is unaffordable for middle-income and low-income people of Pakistan [16-18]. This holds true not only for Pakistan but for other countries as well. A study conducted across 49 European countries elucidated that there are disparities in the availability of cancerous medicines, which are responsible for their inequitable access [19].

The unavailability or unaffordability issues would not only aggravate the underlying disease but also lead to the inequities between the patients. Up till now, numerous studies focusing on the gravity of underlying problems have been conducted in multiple countries, excluding Pakistan. The aim of current study is to assess the availability of anticancer medicines in public and private sectors, and their affordability by high, middle, and low-income class patients.

\section{Methods \\ Study design and settings}

A descriptive, cross-sectional study design was employed. There are total 23 (18 public and four private sector tertiary care) hospitals in Punjab province of Pakistan which provide services to cancer patients. Out of these 23 hospitals, seven were specialized cancer-care hospitals. One hospital was excluded from the survey because it provides services solely to the pediatrics. Survey was carried out in 22 cancer-care hospitals and 44 private pharmacies in Punjab, a province of Pakistan. Data were collected from the pharmacies and cancer patients attending selected hospitals and evaluated according to the objectives of study.

\section{Study population and sample size}

The population under study was cancer patients aged $\geq 18$ years, who visited the selected cancer-care hospitals for routine examinations. According to the latest Pakistani census, the population of the surveyed province consisted of 101,391,000 individuals [20]. The minimum sample size was 4147 as calculated by the Raosoft sample size calculator [21] based on cancer prevalence in Pakistan. With contingency of $5 \%$ for non-response and inappropriate responses, the final sample was calculated to be 4400 . 


\section{Data collection and outcome variables}

A total of 4913 cancer patients were approached over a six month period (1st January, 2017 to 30th June, 2017), 4400 patients consented to participate (response rate $=89.6 \%$ ). Data was collected at different intervals from the selected cancer-care hospitals.

A data collection form was designed for this study which consisted of three main parts: (1) sociodemographic characteristics, (2) diagnosis and (3) recommended medicines. The reliability of the survey tool was assessed by conducting a pilot study. Piloting was undertaken using data from 100 patients. After piloting, the data collection form was restructured.

\section{Measurements}

\section{Socio-demographic characteristics}

Socio-demographic characteristics given in Table 1 were recorded for each participant. Those participants who were retired (taking pension) or running a business were classified as employed and housewives were considered as unemployed. The data was obtained through face to face questioning of patients. To avoid biasness, the data regarding employment status and income level of the participants was validated by using online tax payer verification system of Federal Board of Revenue (FBR) [22].

\section{Diagnosis and prescribing pattern}

The type of cancer and all the medicines present in each prescription were noted on a pre-designed performa sheet. Anticancer medicines having more than one active ingredient were not evaluated. The most commonly prescribed anticancer medicines were categorized according to the prescribing trend; low (prescribed to $<5 \%$ of the selected patients), medium (prescribed to $\geq 5 \%$ of the selected patients but $<10 \%$ ) and high (prescribed to $>10 \%$ of the selected patients).

\section{Availability of anticancer medicines and their per month cost} Forty anticancer medicines were chosen for the survey. These anticancer medicines were selected on the basis of, (a) pilot study in which local needs and cancer burden was assessed, (b) literature review, and (c) the opinions of various experts. During the survey, if medicines were present at the pharmacy settings then they considered as available.

The availability of anticancer medicines was evaluated in public hospitals, private hospitals, and private pharmacies. For the assessment of prices associated with these medicines, Pharmaguide 2016, was consulted [23]. The process of data collection was done by trained pharmacy students under the supervision of survey manager and principal investigator. Principal investigator checked the collected and completed Performa's on weekly basis. If any information was found missing then a follow up visit to the respective setting was conducted. Before initiation of the process of data collection, medical superintendents/directors were contacted by the principal investigator. In this way a good cooperation was established between the team of investigators and the staff members of the selected settings. To avoid report biasness (e.g. up coding, less availability of medicine to gain attention for budget increase, etc.), the drugs were said to be available if they were present in the settings and the patients could avail them on prescription. Also, the formulary list and purchase records were assessed for data validation. For each medicine, data were collected on the basis of per unit price, and availability of OBs and LPGs. On the basis of standard guidelines and the recommended treatment, per unit price of anticancer agents were transformed into per month cost.

Furthermore, the following criteria were used to describe the availability of medicines:

Absent: $0 \%$ of facilities: these medicines were not found in any facility surveyed;

Low: $<50 \%$ of facilities: these medicines were hard to find;

Fairly high: $50-74 \%$ of facilities: these medicines were available in many facilities;

High: $>75 \%$ of facilities: good availability.

\section{Affordability of anticancer medicines}

According to the WHO and Health Action International (HAI) methodology, for the assessment of affordability we have to calculate that "the income of how many days is required to purchase the medicines for 30 days (in case of chronic condition e.g. cancer)". Generally, if the total cost of therapy for 1 month is equal to or less than the wage of 1 day then it is said to be affordable.

A study published by Rasha Khatib et al. [24] defined it as; "if the combined cost of therapy is $<20 \%$ of household capacity-to-pay then it can be considered as affordable." In this study this concept modified and affordability was measured for each prescribed medicine by low, middle, and high income class of patients through this formula;

$$
\text { Affordability }=\frac{\% * \text { of household capacity to pay }}{\text { Per month cost of the medicine }} \times 100
$$

* If 1 medicine was prescribed it was 20\%, if 2 medicines were prescribed it was $10 \%$, if 3 medicines were prescribed it was $6.7 \%$ and if 4 medicines were prescribed it was $5 \%$ of household capacity to pay.

\section{Statistical analysis}

Statistical Package for Social Sciences (IBM, SPSS Statistics for Windows, version 21.0. Armonk, NY: IBM Corp.) was used for data analysis. Descriptive statistics such as frequencies, percentages, and mean were used to present the data. 


\section{Results}

Four thousand four hundred cancer patients were investigated in the study. Just over half $(55.4 \%, n=2436)$ of the participants were male, and $39.3 \%(n=1731)$ were aged 18-39 years. 67.9\% $(n=2987)$ were married, $67.8 \%(n=2981)$ had secondary education level and $40.7 \%(n=1791)$ had income status of upper class. $61.9 \%(n=2723)$ respondents were employed and three-quarters $(73.2 \%, n=3291)$ were urban residents (Table 1).

The most common cancers diagnosed among participants were; non-hodgkin lymphoma (NHL) (12.3\%, $n$ $=540)$, breast cancer $(8.6 \%, n=378)$ and leukemia $(7.6 \%, n=334)$ (Table 2).

The most commonly prescribed anticancer medicines were: cisplatin (49.5\%, $n=2177)$, etoposide (25.8\%, $n=1137)$, and cyclophosphamide (19.9\%, $n=$ 877). The detailed description about the prescribed anticancer medicines is given in Table 3 .

\section{Availability of anticancer medicines (originator brands and lowest price generics)}

The mean availability of anticancer medicines in both public and private sectors was found to be $52.5 \%$ for OBs, while $28.1 \%$ for LPGs. Furthermore, study revealed a fairly high availability for OBs while generally low availability for LPGs. The availability of Fluorouracil (97\%), Etoposide (95.5\%), Methotrexate (95.5\%) and Tamoxifen (95.5\%) was maximal among the OBs; whereas, Gemicitabine (81.1\%), Bleomycin (56.1\%) and Doxorubicin (56.1\%) had the highest availability amongst LPGs in all study settings (see Table 4).

\section{Affordability at different income levels}

The affordability of anticancer medicines (OBs and LPGs) by high, middle, and low-income class patients is listed in Table 5. Patients with high income level could afford the expenditures on anticancer medicines; reverse was true for low income level patients. The most affordable LPGs (afforded by $100 \%$ patients) for low income class patients include Cytarabine, Flourouracil, Mercaptopurine, Methotrexate, Mitomycin and Tamoxifen, respectively.

\section{Discussion}

The initial step for cancer control and prevention is to develop the proper understanding of relationship between disease and demographics [25]. This study reported 73.2\% of the cases from urban areas and $26.8 \%$ from rural areas. Many cancer cases remained undiagnosed in Pakistan due

Table 1 Characteristics of the study population

\begin{tabular}{|c|c|c|c|c|}
\hline \multicolumn{2}{|l|}{ Variables } & $\begin{array}{l}\text { Male }(n=2436) \\
\mathrm{n}(\%)\end{array}$ & $\begin{array}{l}\text { Female }(n=1964) \\
\mathrm{n}(\%)\end{array}$ & \multirow{2}{*}{$\begin{array}{l}\text { Total }(n=4400) \\
\mathrm{n}(\%)\end{array}$} \\
\hline \multirow{4}{*}{ Age (years) } & & & & \\
\hline & $18-39$ & $959(39.4)$ & $772(39.3)$ & $1731(39.3)$ \\
\hline & $40-64$ & $780(32.0)$ & $866(44.1)$ & $1646(37.4)$ \\
\hline & $\geq 65$ & $697(28.6)$ & $326(16.6)$ & $1023(23.3)$ \\
\hline \multirow[t]{4}{*}{ Civil Status } & Single & $84(3.4)$ & $43(2.2)$ & $127(2.9)$ \\
\hline & Married & $1722(70.7)$ & $1265(64.4)$ & $2987(67.9)$ \\
\hline & Widowed & $370(15.2)$ & $514(26.2)$ & $884(20.1)$ \\
\hline & Divorced & $260(10.7)$ & $142(7.2)$ & $402(9.1)$ \\
\hline \multirow[t]{3}{*}{ Education level } & Primary ( $\leq 10$ years) & $503(20.6)$ & $0(0.0)$ & $503(11.4)$ \\
\hline & Secondary (11-13 years) & $1389(57.0)$ & $1592(81.1)$ & $2981(67.8)$ \\
\hline & Tertiary ( $\geq 14$ years) & $544(22.3)$ & $372(18.9)$ & $916(20.8)$ \\
\hline \multirow[t]{3}{*}{ Annual income } & Low class (PKR0-299,999) & $662(27.2)$ & $481(24.5)$ & $1143(26.0)$ \\
\hline & Middle class (PKR300,000-999,999) & $842(34.6)$ & $624(31.8)$ & $1466(33.3)$ \\
\hline & Upper class (PKR $\geq 1,000,000)$ & $932(38.3)$ & $859(43.7)$ & $1791(40.7)$ \\
\hline \multirow[t]{2}{*}{ Employment Status } & Employed & $2138(87.8)$ & $585(29.8)$ & $2723(61.9)$ \\
\hline & Unemployed & $298(12.2)$ & $1379(70.2)$ & $1677(38.1)$ \\
\hline \multirow[t]{2}{*}{ Residence } & Rural & $855(35.1)$ & $326(16.6)$ & $1181(26.8)$ \\
\hline & Urban & $1581(64.9)$ & $1638(83.4)$ & $3219(73.2)$ \\
\hline \multirow[t]{4}{*}{ Number of medicines } & 1 & $67(2.8)$ & $157(8)$ & $224(5.1)$ \\
\hline & 2 & $1768(72.6)$ & $1204(61.3)$ & $2972(67.5)$ \\
\hline & 3 & $559(22.9)$ & $532(27.1)$ & $1091(24.8)$ \\
\hline & 4 & $42(1.7)$ & $71(3.6)$ & $113(2.6)$ \\
\hline
\end{tabular}


Table 2 Cancer cases diagnosed in the study population

\begin{tabular}{|c|c|c|c|c|c|}
\hline Sr. No & Cancer & $1 C D-10$ & $\begin{array}{l}\text { Male }(n=2436) \\
\mathrm{n}(\%)\end{array}$ & $\begin{array}{l}\text { Female }(n=1964) \\
\mathrm{n}(\%)\end{array}$ & $\begin{array}{l}\text { Total }(n=4400) \\
\mathrm{n}(\%)\end{array}$ \\
\hline 1 & Bladder & C67 & $42(1.7)$ & $32(1.6)$ & $74(1.7)$ \\
\hline 2 & Brain & C70-72 & $111(4.6)$ & $70(3.6)$ & $181(4.1)$ \\
\hline 3 & Breast & C50 & - & 378 (19.2) & $378(8.6)$ \\
\hline 4 & Cervix uteri & C53 & - & $142(7.2)$ & $142(3.2)$ \\
\hline 5 & Colorectal & C18-21 & $131(5.4)$ & $43(2.2)$ & $174(4.0)$ \\
\hline 6 & Corpus uteri & C54 & - & $71(3.6)$ & $71(1.6)$ \\
\hline 7 & Gallbladder & C23-24 & $110(4.5)$ & $71(3.6)$ & $181(4.1)$ \\
\hline 8 & Hodgkin lymphoma & C81 & $149(6.1)$ & $43(2.2)$ & $192(4.4)$ \\
\hline 9 & Kidney & C64-66 & $178(7.3)$ & $114(5.8)$ & $292(6.6)$ \\
\hline 10 & Larynx & C32 & $111(4.6)$ & $70(3.6)$ & $181(4.1)$ \\
\hline 11 & Leukemia & C91-95 & $221(9.1)$ & $113(5.8)$ & $334(7.6)$ \\
\hline 12 & Lip, oral cavity & COO-08 & $110(4.5)$ & $70(3.6)$ & $180(4.1)$ \\
\hline 13 & Liver & C22 & $111(4.6)$ & $70(3.6)$ & $181(4.1)$ \\
\hline 14 & Lung & C33-34 & $186(7.6)$ & $104(5.3)$ & $290(6.6)$ \\
\hline 15 & Non-Hodgkin lymphoma & C82-85 & $363(14.9)$ & $177(9.0)$ & $540(12.3)$ \\
\hline 16 & Esophagus & C15 & $107(4.4)$ & $71(3.6)$ & $178(4.0)$ \\
\hline 17 & Ovary & C56 & - & $141(7.2)$ & $141(3.2)$ \\
\hline 18 & Pancreas & $C 25$ & $111(4.6)$ & $70(3.6)$ & $181(4.1)$ \\
\hline 19 & Prostate & C61 & $220(9.0)$ & - & $220(5.0)$ \\
\hline 20 & Stomach & C16 & $65(2.7)$ & $43(2.2)$ & $108(2.5)$ \\
\hline 21 & Thyroid & C73 & $110(4.5)$ & $71(3.6)$ & $181(4.1)$ \\
\hline
\end{tabular}

to financial obstacles and poor availability of health care facilities (e.g. inadequate system of population based registers, and deprived diagnosis as well as treatment facilities in rural areas as compared to urban areas) $[26,27]$. Therefore, exact number of cancer cases might be far greater in number than that of reported.

Breast cancer (19.2\%) was the most commonly diagnosed cancer among females while NHL (14.9\%) was commonly found in males. Such a high prevalence of breast cancer is not only found in Pakistan, it can be seen throughout the world. It is estimated that nearly half of all the reported cases of breast cancer and 38\% of all the deaths due to this fatal illness have been reported from developed countries. The various subtypes of NHL are thought to alter immune system and show different pattern of incidence.

\section{Availability of anticancer medicines (originator brands and lowest price generics)}

The availability of anti-cancerous medicines is mandatory for saving lives of cancer patients. In many low and middle income countries (LMICs) the availability of LPGs is often less [28] e.g., a cross-sectional study conducted in Dar es Salaam (Tanzania) revealed that the availability of anticancer drugs in healthcare settings was $50 \%$ of the total surveyed medicines while only $30 \%$ of the patients could get the anticancer drugs from the healthcare settings [29]. Similarly, the current findings showed that in both sectors the overall availability of OBs (52.5\%) can be considered as fairly high in comparison with the LPGs (28.1\%). Most of the OBs are the products of the multinational pharmaceutical companies (MPCs). These MPCs adopt various strategies (e.g., promotional techniques and the patent rights) in order to compete with the local pharmaceutical companies (LPCs). Due to the limitation of resources, LPCs cannot manage budget for promotional strategies. The promotional efforts of MPCs make product well-familiar to the prescribers. Therefore, prescribers are compelled to prescribe these medicines. According to the Trade-Related Aspects of Intellectual Property Rights (TRIPS) agreement, Pakistan has a right to include in its patent legislation a provision to manufacture LPGs without the requisition of any consent from the patent holder since Pakistan is a member of World Trade Organization (WTO). But, it was also found that 10 medicines LPGs were not available in the market.

In LMICs, the availability of medicines in the healthcare settings is considerably influenced by the cost [30]. This study revealed that the availability of these 
Table 3 Anticancer medicines prescribed to study participants

\begin{tabular}{|c|c|c|c|c|c|c|c|c|}
\hline Sr. No & Medicine and Dose & $\begin{array}{l}\text { ATC } \\
\text { Code }\end{array}$ & $f(n=9893) \%^{a}$ & Trend & $\mathrm{OB}$ & $\begin{array}{l}\text { Per month } \\
\text { cost }\end{array}$ & LPG & $\begin{array}{l}\text { Per month } \\
\text { cost }\end{array}$ \\
\hline 1 & Anastrozole $1 \mathrm{mg}$ tab & L02BG03 & $71(1.6)$ & Low & Anastrozole (Novartis) & 6000 & Femizet (Atco) & 5130 \\
\hline 2 & Bicalutamide $50 \mathrm{mg}$ tab & L02BB03 & $109(2.5)$ & Low & Casodex (ICI) & 12,642 & Calutide (A. J. Mirza) & 4308 \\
\hline 3 & Bleomycin 15 mg inj & L01 DC01 & $42(1.0)$ & Low & $\begin{array}{l}\text { Bleomycin } \\
\text { (Pharmedic) }\end{array}$ & 9960 & Bemocin (Atco) & 8000 \\
\hline 4 & Capecitabine 500 mg tab & L01 BC06 & $258(5.9)$ & Medium & Xeloda (Roche) & 25,000 & NA & NA \\
\hline 5 & Carboplatin 150 mg inj & L01XA02 & $206(4.7)$ & Low & Carpsol (Pfizer) & 6681 & Carboplatin (Atco) & 3000 \\
\hline 6 & Cisplatin 50 mg inj & L01XA01 & $2177(49.5)$ & High & Cisplasol (Pfizer) & 3099 & $\begin{array}{l}\text { Platosin } \\
\text { (Pharmachemie) }\end{array}$ & 1750 \\
\hline 7 & $\begin{array}{l}\text { Cyclophosphamide } \\
500 \text { mg inj }\end{array}$ & L01AA01 & $877(19.9)$ & High & Cyclomide (Pharmedic) & 5625 & $\begin{array}{l}\text { Cyclophosphamide } \\
\text { (S. Ejazuddin) }\end{array}$ & 3000 \\
\hline 8 & $\begin{array}{l}\text { Cyproterone Acetate } \\
50 \mathrm{mg} \text { tab }\end{array}$ & G03HA01 & $66(1.5)$ & Low & Androcur (Bayer) & 3588 & NA & NA \\
\hline 9 & Cytarabine $100 \mathrm{mg}$ inj & L01 BC01 & $342(7.8)$ & Medium & Cytosar (Pfizer) & 2700 & Cytarabine (Highnoon) & 1785 \\
\hline 10 & Dacarbazine 200 mg inj & L01AX04 & $74(1.7)$ & Low & Duticin (Al-Habib) & 2700 & Darbazine (Pharmedic) & 2500 \\
\hline 11 & Dactinomycin 0.5 mg inj & L01DA01 & $71(1.6)$ & Low & Dactinomycin (Al-Habib) & 28,616 & Dactinofin (Pharmedic) & 23,520 \\
\hline 12 & Daunomycin 20 mg inj & L01DB02 & $111(2.5)$ & Low & Daunoblastina (Pfizer) & 6750 & D-Blastin (Pharmedic) & 5700 \\
\hline 13 & Docetaxil $80 \mathrm{mg}$ inj & L01CD02 & $18(0.4)$ & Low & Taxotere (Sanofi aventis) & 76,000 & Docekebir (Oncogene) & 74,400 \\
\hline 14 & Doxorubicin $50 \mathrm{mg}$ inj & L01DB01 & $385(8.8)$ & Medium & Adriblastina (Pfizer) & 4495 & Doxorubicin (Al- Habib) & 3170 \\
\hline 15 & Epirubicin 50 mg inj & L01DB03 & $427(9.7)$ & Medium & Farmorubicin (Pfizer) & 13,270 & Anthracin (Atco) & 9510 \\
\hline 16 & Etoposide 100 mg inj & L01CB01 & $1137(25.8)$ & High & Etoposide (Pfizer) & 7150 & Lymphoside (CCL) & 4950 \\
\hline 17 & $\begin{array}{l}\text { Fludarabine phosphate } \\
50 \mathrm{mg} \text { inj }\end{array}$ & L01BB05 & $180(4.1)$ & Low & Fludara (Sanofi aventis) & 66,313 & Fludakebir (Oncogene) & 46,400 \\
\hline 18 & Flourouracil 500 mg inj & L01 BC02 & $502(11.4)$ & High & $\begin{array}{l}\text { Pharmauracil } \\
\text { (Pharmedic) }\end{array}$ & 1944 & Secouracil (S. Ejazuddin) & 176 \\
\hline 19 & Gemicitabine $1 \mathrm{~g}$ inj & L01 BC05 & $685(15.6)$ & High & Gemzar (Eli lilly) & 64,020 & Gemita (Atco) & 41,650 \\
\hline 20 & Hydroxyurea 500 mg cap & L01XX05 & $43(1.0)$ & Low & Hydra (Medinet) & 1200 & Hydrine (Al-Habib) & 1168 \\
\hline 21 & Ifosfamide I gminj & L01AA06 & $71(1.6)$ & Low & Ifosfamin (Pharmedic) & 12,000 & Fosfamin (CCL) & 12,000 \\
\hline 22 & $\begin{array}{l}\text { Imatinibmesylate } \\
400 \text { mg tab }\end{array}$ & L01XE01 & $67(1.5)$ & Low & Glivec (Novartis) & 140,000 & NA & NA \\
\hline 23 & Irinotecan 100 mg inj & L01XX19 & $181(4.1)$ & Low & Campto (Pfizer) & 133,480 & Irinocan (Pharmedic) & 71,250 \\
\hline 24 & Lapatinib 250 mg tab & L01XE07 & $43(1.0)$ & Low & Tykerb (GSK) & 201,650 & NA & NA \\
\hline 25 & Letrozole $2.5 \mathrm{mg}$ tab & L02BG04 & $71(1.6)$ & Low & Femara (Novartis) & 8720 & Letara (A.J. Mirza) & 5100 \\
\hline 26 & $\begin{array}{l}\text { Mercaptopurine } \\
50 \mathrm{mg} \text { tab }\end{array}$ & L01BB02 & $111(2.5)$ & Low & $\begin{array}{l}\text { Mercaprine } \\
\text { (Pharmedia) }\end{array}$ & 741 & Purinetone (Al- Habib) & 630 \\
\hline 27 & Methotrexate $10 \mathrm{mg}$ tab & L01BA01 & $72(1.6)$ & Low & $\begin{array}{l}\text { Emthexate } \\
\text { (Pharmachemie) }\end{array}$ & 817 & Unitrexate (Al-Habib) & 410 \\
\hline 28 & Mitomycin 10 mg inj & L01 DC03 & $71(1.6)$ & Low & Mitocin (Pharmedic) & 2256 & Mitomycin (S.Ejazuddin) & 232 \\
\hline 29 & Mitoxantrone 20 mg inj & L01DB07 & $43(1.0)$ & Low & Mitoxantrona (Atco) & 4000 & NA & NA \\
\hline 30 & Nilotinib 200 mg cap & L01XE08 & $43(1.0)$ & Low & Tasigna (Novartis) & 456,000 & NA & NA \\
\hline 31 & Oxalplatin $100 \mathrm{mg}$ inf & L01XA03 & $288(6.5)$ & Medium & Oxitan (Atco) & 60,000 & Eloxatin (Sanofi aventis) & 52,500 \\
\hline 32 & Paclitaxel $260 \mathrm{mg}$ inf & L01CD01 & $71(1.6)$ & Low & Intaxel (Atco) & 34,600 & Paclixil (A.J. Mirza) & 34,600 \\
\hline 33 & Pazopanib 400 mg tab & L01XE11 & $67(1.5)$ & Low & Votrient (GSK) & 176,666 & NA & NA \\
\hline 34 & Sorafenib 200 mg tab & L01XE05 & $43(1.0)$ & Low & Nexavar (Bayer) & 465,600 & NA & NA \\
\hline 35 & Sunitinib 50 mg cap & L01XE04 & $67(1.5)$ & Low & Sutent (Pfizer) & 392,640 & NA & NA \\
\hline 36 & Tamoxifen 20 mg tab & L02BA01 & $71(1.6)$ & Low & Tamox (Pharmedic) & 600 & Tamooxe (Al-Habib) & 450 \\
\hline 37 & Thalidomide 100 mg cap & L04AX02 & $43(1.0)$ & Low & Thalido(Atco) & 6000 & NA & NA \\
\hline
\end{tabular}


Table 3 Anticancer medicines prescribed to study participants (Continued)

\begin{tabular}{|c|c|c|c|c|c|c|c|c|}
\hline Sr. No & Medicine and Dose & $\begin{array}{l}\text { ATC } \\
\text { Code }\end{array}$ & $f(n=9893) \%^{a}$ & Trend & $\mathrm{OB}$ & $\begin{array}{l}\text { Per month } \\
\text { cost }\end{array}$ & LPG & $\begin{array}{l}\text { Per month } \\
\text { cost }\end{array}$ \\
\hline 38 & Vinblastine $10 \mathrm{mg}$ inj & L01CA01 & $42(1.0)$ & Low & Velbastine (Al-Habib) & 4165 & Vinblas (Pharmedic) & 2800 \\
\hline 39 & Vincristine 2 mg inj & L01CA02 & $522(11.9)$ & High & $\begin{array}{l}\text { Pharmacristine } \\
\text { (Pharmedic) }\end{array}$ & 1580 & $\begin{array}{l}\text { Vincristine Gador } \\
\text { (Seignior) }\end{array}$ & 1124 \\
\hline 40 & Vinorelbine 50 mg inj & L01CA04 & $71(1.6)$ & Low & Vinelbine (Atco) & 33,480 & Vinkebir (Oncogene) & 33,480 \\
\hline
\end{tabular}

anticancer medicines was high in the private sector (71.9\% for OBs and $20.0 \%$ for LPGs) as compared to the government healthcare settings $(31.4 \%$ for OBs and $11.7 \%$ LPGs). Due to financial constraints, the government of Pakistan is unable to maintain good infrastructure of the public healthcare settings [31]. Thus government hospitals often face the issue of unavailability or shortage of medicines as compared to private sectors.

Unlike the conventional medicines new anticancer medicines were less readily available in both sectors. In LMICs like Pakistan, the retail prices are the major deterrent to access when compared with the cost at the supplier level [32]. In Pakistan, the high taxation associated with these lifesaving medicines is a cruel joke with the cancer sufferers. All the national and international organizations i.e., the WHO, HAI, The United States Agency for International Development (USAID), United Nations Organization (UNO) and DRAP must provide adequate funding so that tax free anticancer medicines can be made available to the local masses.

\section{Affordability of anticancer medicines at different income levels}

In Pakistan, the affordability of medicines, especially anticancer medicines, is widely affected by the proliferation of OBs [12]. Our findings showed that the LPGs (67.9\%) are more affordable than the OBs (53.4\%). Because of price constraints medicines are not $100 \%$ affordable for general public, so OBs were found to be more affordable (70.7\%) for high income patients, less affordable (49.1\%) for middle income patients, and least affordable (29.2\%) for low income patients. This may cause a great risk of disease progression, higher rate of mortalities and morbidities. In this study, the overall affordability for both OBs and LPGs was found to be 55.5\% which makes cancer a catastrophic disease for local masses [33]. Another dilemma of LMICs is that the local masses are unaware of the importance of health insurance [34]. But sometimes these insurance policies fail to provide benefits or demand substantial co-payment [35]. Private health insurance schemes cover medicines cost. But high inflation, low per capta income and increasing cost of living are among the several hurdles that hinder the individuals for buying private health insurance and pay monthly premium. The government hospitals of Pakistan do not require any copayment for consultation and medicines. But in private hospitals all the expenses have to be paid by the patient [36]. Therefore, in 2014 Pakistani government took initiative in the form of Prime Minister National Health Insurance Program. This program aimed to cover a large number of cancer sufferers in both government and private sector. But without the cooperation of international organizations, this program cannot cover all the financially constrained civilians of Pakistan.

\section{Strength and limitations}

There is no previously published study that evaluates the anticancer medicines with respect to availability in public and private sectors, and affordability with respect to income class especially in LMICs like Pakistan. Our study will provide a door to the researchers of other LMICs to evaluate availability and affordability related barriers towards optimal cancer treatment in their respective settings so that cancer medicines can be made affordable all over the entire globe.

There are some limitations in this study. First, the availability was measured at 'one time' on the day of data collection from any health facility. Therefore some facilities might usually have a product is available, but the drug may be out of stock on the day of data collection. Second, although this paper contains data on availability of anticancer drugs in Pakistan but it does not give insight in to what extent current guidelines of drug treatment of cancer are compromised by limited access to anticancer drugs. So, we cannot conclude what the effect of this is to outcome of anticancer treatment in Pakistan patients. Third, the authors measured households' capacity to pay by collecting household income information, though it is often recommended that household ordinary expenditure excluding durable goods consumption will better reflect household's capacity to pay. 
Table 4 Availability of anticancer medicines in public and private sectors in Punjab, Pakistan

\begin{tabular}{|c|c|c|c|c|c|c|c|c|c|}
\hline \multirow[t]{2}{*}{ Sr. No } & \multirow[t]{2}{*}{ Medicine and Dose } & \multicolumn{2}{|c|}{ Public hospitals $(n=18)$} & \multicolumn{2}{|c|}{ Private hospitals $(n=4)$} & \multicolumn{2}{|c|}{ Private pharmacies $(n=44)$} & \multicolumn{2}{|c|}{ All $(n=66)$} \\
\hline & & $\mathrm{OB}$ & LPG & $\mathrm{OB}$ & LPG & $\mathrm{OB}$ & LPG & $\mathrm{OB}$ & LPG \\
\hline 1 & Anastrozole 1 mg tab & $0(0.0)$ & $0(0.0)$ & $1(25.0)$ & $0(0.0)$ & $4(9.1)$ & $2(4.5)$ & $5(7.6)$ & $2(3.0)$ \\
\hline 2 & Bicalutamide 50 mg tab & $0(0.0)$ & $0(0.0)$ & $1(25.0)$ & $0(0.0)$ & $3(6.8)$ & $1(2.3)$ & $4(6.1)$ & $1(1.5)$ \\
\hline 3 & Bleomycin 15 mg inj & $10(55.6)$ & $8(44.4)$ & $4(100)$ & $2(50.0)$ & $41(93.2)$ & $27(61.4)$ & $55(83.3)$ & $37(56.1)$ \\
\hline 4 & Capecitabine 500 mg tab & $4(22.2)$ & NA & $4(100)$ & NA & $21(47.7)$ & NA & $29(44.0)$ & NA \\
\hline 5 & Carboplatin 150 mg inj & $13(72.2)$ & $5(27.8)$ & $4(100)$ & $1(25.0)$ & $33(75.0)$ & $29(65.9)$ & $50(76.0)$ & $35(53.0)$ \\
\hline 6 & Cisplatin 50 mg inj & $8(44.4)$ & $9(50.0)$ & $3(75.0)$ & $0(0.0)$ & $43(97.7)$ & $11(25.0)$ & $54(82.0)$ & $20(30.3)$ \\
\hline 7 & Cyclophosphamide 500 mg inj & $15(83.3)$ & $3(16.7)$ & $4(100)$ & $0(0.0)$ & $41(93.2)$ & $9(20.5)$ & $60(91.0)$ & $12(18.2)$ \\
\hline 8 & Cyproterone Acetate 50 mg tab & $7(38.9)$ & NA & $4(100)$ & NA & 39 (88.6) & NA & $50(76.0)$ & NA \\
\hline 9 & Cytarabine 100 mg inj & $3(16.7)$ & $0(0.0)$ & $3(75.0)$ & $1(25.0)$ & $34(77.3)$ & $7(15.9)$ & $40(61.0)$ & $8(12.1)$ \\
\hline 10 & Dacarbazine 200 mg inj & $4(22.2)$ & $1(5.6)$ & $2(50.0)$ & $1(25.0)$ & $27(61.4)$ & $13(29.5)$ & $33(50.0)$ & $15(22.7)$ \\
\hline 11 & Dactinomycin 0.5 mg inj & $8(44.4)$ & $2(11.1)$ & $3(75.0)$ & $1(25.0)$ & $42(95.5)$ & $31(70.5)$ & $53(80.3)$ & $34(51.5)$ \\
\hline 12 & Daunomycin 20 mg inj & $2(11.1)$ & $0(0.0)$ & $1(25.0)$ & $1(25.0)$ & $16(36.4)$ & $11(25.0)$ & $19(29.0)$ & $12(18.2)$ \\
\hline 13 & Docetaxil 80 mg inj & $7(38.9)$ & $0(0.0)$ & $3(75.0)$ & $0(0.0)$ & $33(75.0)$ & $7(15.9)$ & $43(65.1)$ & $7(10.6)$ \\
\hline 14 & Doxorubicin 50 mg inj & $14(77.8)$ & $4(22.2)$ & $4(100)$ & $2(50.0)$ & $44(100)$ & $31(70.5)$ & $62(94.0)$ & $37(56.1)$ \\
\hline 15 & Epirubicin 50 mg inj & $2(11.1)$ & $3(16.7)$ & $4(100)$ & $1(25.0)$ & 14(31.8) & $9(20.5)$ & $20(30.3)$ & $13(19.7)$ \\
\hline 16 & Etoposide 100 mg inj & $15(83.3)$ & $0(0.0)$ & $4(100)$ & $0(0.0)$ & 44(100) & $13(29.5)$ & $63(95.4)$ & $13(19.7)$ \\
\hline 17 & Fludarabine phosphate 50 mg inj & $0(0.0)$ & $0(0.0)$ & $4(100)$ & $1(25.0)$ & $11(25.0)$ & $4(9.9)$ & $15(23.0)$ & $5(7.6)$ \\
\hline 18 & Flourouracil 500 mg inj & $16(88.9)$ & $0(0.0)$ & $4(100)$ & $2(50.0)$ & $44(100)$ & $19(43.2)$ & $64(97.0)$ & $21(31.8)$ \\
\hline 19 & Gemicitabine $1 \mathrm{~g}$ inj & $5(27.8)$ & $11(61.1)$ & $4(100)$ & $2(50.0)$ & $31(70.5)$ & $41(93.2)$ & $40(61.0)$ & $54(81.8)$ \\
\hline 20 & Hydroxyurea 500 mg cap & $7(38.9)$ & $0(0.0)$ & $3(75.0)$ & $0(0.0)$ & $23(52.3)$ & $11(25.0)$ & $33(50.0)$ & $11(16.7)$ \\
\hline 21 & Ifosfamide I gminj & $5(27.8)$ & $2(11.1)$ & $2(50.0)$ & $0(0.0)$ & 19(42.3) & $21(47.7)$ & $26(39.4)$ & $21(31.8)$ \\
\hline 22 & Imatinibmesylate 400 mg tab & $0(0.0)$ & NA & $3(75.0)$ & NA & 15(34.1) & NA & $18(27.3)$ & NA \\
\hline 23 & Irinotecan 100 mg inj & $0(0.0)$ & $0(0.0)$ & $2(50.0)$ & $0(0.0)$ & $11(25.0)$ & $10(22.7)$ & $13(20.0)$ & $10(15.2)$ \\
\hline 24 & Lapatinib 250 mg tab & $0(0.0)$ & NA & $2(50.0)$ & NA & 13(29.6) & NA & $15(23.0)$ & NA \\
\hline 25 & Letrozole $2.5 \mathrm{mg}$ tab & $0(0.0)$ & $0(0.0)$ & $2(50.0)$ & $0(0.0)$ & $16(36.4)$ & $8(18.2)$ & $18(27.2)$ & $8(12.1)$ \\
\hline 26 & Mercaptopurine 50 mg tab & $13(72.2)$ & $3(16.7)$ & $4(100)$ & $0(0.0)$ & $41(93.2)$ & $11(25.0)$ & $58(88.0)$ & $14(21.2)$ \\
\hline 27 & Methotrexate $10 \mathrm{mg}$ tab & $15(83.3)$ & $1(5.6)$ & $4(100)$ & $1(25.0)$ & $44(100)$ & $19(43.2)$ & $63(95.4)$ & $21(31.8)$ \\
\hline 28 & Mitomycin 10 mg inj & $2(11.1)$ & $0(0.0)$ & $2(50.0)$ & $1(25.0)$ & $31(70.5)$ & $12(27.3)$ & $35(53.0)$ & $13(19.7)$ \\
\hline 29 & Mitoxantrone 20 mg inj & $0(0.0)$ & NA & $3(75.0)$ & NA & $18(40.9)$ & NA & $21(32.0)$ & NA \\
\hline 30 & Nilotinib 200 mg cap & $0(0.0)$ & NA & $3(75.0)$ & NA & $19(43.2)$ & NA & $22(33.3)$ & NA \\
\hline 31 & Oxaliplatin 100 mg inf & $1(5.6)$ & $0(0.0)$ & $2(50.0)$ & $2(50.0)$ & $21(47.7)$ & $11(25.0)$ & $24(36.4)$ & $13(19.7)$ \\
\hline 32 & Paclitaxel 260 mg inf & $11(61.1)$ & $4(22.2)$ & $3(75.0)$ & $1(25.0)$ & $44(100)$ & $23(52.3)$ & $58(88.0)$ & $28(42.4)$ \\
\hline 33 & Pazopanib 400 mg tab & $0(0.0)$ & NA & $1(25.0)$ & NA & $4(9.1)$ & NA & $5(7.6)$ & NA \\
\hline 34 & Sorfenib 200 mg tab & $0(0.0)$ & NA & $1(25.0)$ & NA & $5(11.4)$ & NA & $6(9.1)$ & NA \\
\hline 35 & Sunitinib 50 mg cap & $0(0.0)$ & NA & $0(0.0)$ & NA & $3(6.8)$ & NA & $3(4.5)$ & NA \\
\hline 36 & Tamoxifen 20 mg tab & $15(83.3)$ & $2(11.1)$ & $4(100)$ & $2(50.0)$ & $44(100)$ & $16(36.4)$ & $63(95.4)$ & $20(30.3)$ \\
\hline 37 & Thalidomide 100 mg cap & $4(22.2)$ & NA & $4(100)$ & NA & $25(56.8)$ & NA & $33(50.0)$ & NA \\
\hline 38 & Vinblastine 10 mg inj & $9(50.0)$ & $3(16.7)$ & $4(100)$ & $0(0.0)$ & $31(70.5)$ & $19(43.2)$ & $44(67.0)$ & $34(51.5)$ \\
\hline 39 & Vincristine 2 mg inj & $11(61.1)$ & $2(11.1)$ & $3(75.0)$ & $0(0.0)$ & $33(75.0)$ & $23(52.3)$ & $47(71.2)$ & $25(37.9)$ \\
\hline 40 & Vinorelbine 50 mg inj & $0(0.0)$ & $0(0.0)$ & $2(50.0)$ & $2(50.0)$ & $21(47.7)$ & $11(25.0)$ & $23(35.0)$ & $13(19.7)$ \\
\hline Total & & $31.4 \%$ & $11.7 \%$ & $71.9 \%$ & $20.0 \%$ & $59.4 \%$ & $34.9 \%$ & $52.5 \%$ & $28.1 \%$ \\
\hline
\end{tabular}


Table 5 Affordability of anticancer medicines by high, middle and low-income class patients in Punjab, Pakistan

\begin{tabular}{|c|c|c|c|c|c|c|c|c|c|c|}
\hline \multirow[t]{2}{*}{ Sr. No. } & \multirow[t]{2}{*}{ Medicine and Dose } & \multicolumn{3}{|l|}{$\mathrm{OB}$} & \multirow[t]{2}{*}{ Overall OB } & \multicolumn{3}{|l|}{ LPG } & \multirow[t]{2}{*}{ Overall LPG } & \multirow{2}{*}{$\begin{array}{l}\text { Overall both } \\
(\mathrm{OB}+\mathrm{LPG})\end{array}$} \\
\hline & & High & Middle & Low & & High & Middle & Low & & \\
\hline 1 & Anastrozole 1 mg tab & 100 & 50.1 & 18.3 & 71.5 & 100 & 68.3 & 20.6 & 63.2 & 68.2 \\
\hline 2 & Bicalutamide 50 mg tab & 100 & 28.2 & 12.4 & 48.9 & 100 & 100 & 73.8 & 93.3 & 66.4 \\
\hline 3 & Bleomycin 15 mg inj & 68.3 & 18.1 & 6.5 & 27.8 & 78.8 & 46.6 & 15.4 & 46.9 & 36.0 \\
\hline 4 & Capecitabine 500 mg tab & 61.9 & 25.0 & 8.1 & 35.5 & NA & NA & NA & NA & 35.5 \\
\hline 5 & Carboplatin 150 mg inj & 100 & 93.1 & 32.7 & 79.3 & 100 & 100 & 77.1 & 93.6 & 85.0 \\
\hline 6 & Cisplatin 50 mg inj & 100 & 100 & 60 & 91.6 & 100 & 100 & 97.5 & 99.3 & 94.4 \\
\hline 7 & Cyclophosphamide 500 mg inj & 100 & 65.5 & 28.0 & 70.5 & 100 & 95.9 & 57 & 86.6 & 77.0 \\
\hline 8 & Cyproterone Acetate 50 mg tab & 100 & 99.5 & 43.8 & 84.5 & NA & NA & NA & NA & 84.5 \\
\hline 9 & Cytarabine 100 mg inj & 100 & 100 & 69.9 & 92.5 & 100 & 100 & 100 & 100 & 94.7 \\
\hline 10 & Dacarbazine 200 mg inj & 100 & 77.8 & 53.6 & 78.3 & 100 & 100 & 67.9 & 90 & 83.4 \\
\hline 11 & Dactinomycin 0.5 mg inj & 100 & 42.6 & 14.7 & 66.1 & 100 & 51.8 & 17.8 & 56.4 & 62.3 \\
\hline 12 & Daunomycin 20 mg inj & 100 & 50.3 & 15.7 & 58.1 & 100 & 100 & 43.3 & 85.6 & 69.0 \\
\hline 13 & Docetaxil 80 mg inj & 31.8 & 5.5 & 3.2 & 15.1 & NP & NP & NP & NP & 15.1 \\
\hline 14 & Doxorubicin 50 mg inj & 100 & 62.5 & 27.8 & 68.7 & 100 & 93.5 & 39.5 & 80.3 & 73.0 \\
\hline 15 & Epirubicin 50 mg inj & 75.3 & 28.6 & 9.0 & 44.2 & 96.4 & 38.1 & 19.1 & 55.3 & 48.6 \\
\hline 16 & Etoposide 100 mg inj & 100 & 77.4 & 31.0 & 74.6 & 100 & 92.4 & 43.9 & 82.1 & 77.6 \\
\hline 17 & Fludarabine phosphate 50 mg inj & 30.1 & 8.2 & 2.8 & 15.9 & 40.3 & 11.1 & 5.1 & 2.7 & 17.8 \\
\hline 18 & Flourouracil 500 mg inj & 100 & 100 & 60.9 & 90.6 & 100 & 100 & 100 & 100 & 94.4 \\
\hline 19 & Gemicitabine $1 \mathrm{~g}$ inj & 21.3 & 9.7 & 3.5 & 13.2 & 32.4 & 13.5 & 5.2 & 18.1 & 15.1 \\
\hline 20 & Hydroxyurea 500 mg cap & 100 & 100 & 100 & 100 & NP & NP & NP & NP & 100 \\
\hline 21 & Ifosfamide I gminj & 62.9 & 29.5 & 9.1 & 42.3 & 62.9 & 29.2 & 8.8 & 33.5 & 38.8 \\
\hline 22 & Imatinibmesylate 400 mg tab & 7.2 & 2.4 & 0.8 & 3.6 & NA & NA & NA & NA & 3.6 \\
\hline 23 & Irinotecan 100 mg inj & 6.7 & 2.2 & 1.0 & 3.8 & 11.6 & 4.4 & 2.1 & 6.5 & 4.9 \\
\hline 24 & Lapatinib 250 mg tab & 8.0 & 3.0 & 1.0 & 5.1 & NA & NA & NA & NA & 5.1 \\
\hline 25 & Letrozole 2.5 mg tab & 86.5 & 40.7 & 12.6 & 58.3 & 100 & 68.7 & 20.7 & 63.3 & 60.3 \\
\hline 26 & Mercaptopurine 50 mg tab & 100 & 100 & 100 & 100 & 100 & 100 & 100 & 100 & 100 \\
\hline 27 & Methotrexate $10 \mathrm{mg}$ tab & 100 & 100 & 100 & 100 & 100 & 100 & 100 & 100 & 100 \\
\hline 28 & Mitomycin 10 mg inj & 100 & 100 & 48.5 & 89.2 & 100 & 100 & 100 & 100 & 93.5 \\
\hline 29 & Mitoxantrone 20 mg inj & 100 & 100 & 52.5 & 90.1 & NA & NA & NA & NA & 90.1 \\
\hline 30 & Nilotinib 200 mg cap & 2.2 & 0.9 & 0.3 & 1.4 & NA & NA & NA & NA & 1.4 \\
\hline 31 & Oxalplatin 100 mg inf & 14.5 & 5.8 & 2.0 & 8.2 & 18.0 & 6.6 & 3.5 & 10.3 & 9.1 \\
\hline 32 & Paclitaxel 260 mg inf & 23.9 & 8.5 & 4.6 & 15.6 & 23.9 & 14.6 & 5.0 & 14.5 & 15.1 \\
\hline 33 & Pazopanib 400 mg tab & 14.8 & 3.5 & 1.4 & 6.8 & NA & NA & NA & NA & 6.8 \\
\hline 34 & Sorafenib 200 mg tab & 6.3 & 3.2 & 1.1 & 4.3 & NA & NA & NA & NA & 4.3 \\
\hline 35 & Sunitinib 50 mg cap & 6.7 & 1.6 & 0.6 & 3.1 & NA & NA & NA & NA & 3.1 \\
\hline 36 & Tamoxifen 20 mg tab & 100 & 100 & 100 & 100 & 100 & 100 & 100 & 100 & 100 \\
\hline 37 & Thalidomide 100 mg cap & 100 & 67.7 & 24.3 & 75.1 & NA & NA & NA & NA & 75.1 \\
\hline 38 & Vinblastine 10 mg inj & 100 & 43.2 & 15.6 & 50.5 & 100 & 100 & 43.9 & 81.3 & 63.7 \\
\hline 39 & Vincristine 2 mg inj & 100 & 100 & 85.2 & 96.3 & 100 & 100 & 99.4 & 99.8 & 97.6 \\
\hline 40 & Vinorelbine 50 mg inj & 100 & 8.7 & 4.8 & 54.6 & 100 & 15.1 & 5.1 & 39.2 & 48.5 \\
\hline Total & & 70.7 & 49.1 & 29.2 & 53.4 & 84.4 & 69.6 & 49.0 & 67.9 & 55.5 \\
\hline
\end{tabular}

$\mathrm{OB}=$ Originator brand; $\mathrm{LPG}=$ Lowest price generic; $\mathrm{NA}=$ Not available; NP: Not prescribed 


\section{Conclusion}

Cancers like non-hodgkin lymphomas and breast cancer are prevalent in Pakistan. The study revealed a fairly high availability for OBs and generally low availability for LPGs. The availability of these agents is greater in private sector as compared to public sector. The overall affordability of LPGs is more as compared to OBs irrespective of the income class; however, both of them are more affordable by high income class patients. Government and regulatory authorities must take adequate steps and formulate such policies to ensure the equitable availability and affordability of cancer medicines to fight against this deadly disease.

\section{Abbreviations}

HAl: Health Action International; LPCs: Local Pharmaceutical Companies; LPGs: Lowest Price Generics; MPCs: Multinational Pharmaceutical Companies; OBs: Originator Brands; SPSS: Statistical Packages for Social Sciences; WHO: World Health Organization

\section{Acknowledgements}

We would like to express wholehearted thankfulness to participants of the study. We wish to express gratitude to Dr. Muhammad Atif (Assistant Professor, Islamia University of Bahawalpur, Pakistan), Dr. Zaheer-Ud-Din Babar (Professor, University of Huddersfield, United Kingdom), Dr. Shane Scahill (Senior Lecturer, Massey University, New Zealand) and Dr. Tayyaba Sadiq (Lecturer, Akhtar Saeed College of Pharmaceutical Sciences, Pakistan) for reviewing and editing the paper and for valuable comments. Also, a note of thanks to all pharmacy students who acted as data collectors.

\section{Funding}

None

\section{Availability of data and materials}

The raw data on which conclusions of this manuscript rely is available upon request. Please contact Muhammad Rehan Sarwar at rehansarwaralvi@gmail.com.

\section{Authors' contributions}

MRS conceptualized and designed the study. AS and SI analyzed and interpreted the data. MRS and AS drafted the manuscript. SI and MRS critically revised the manuscript. All authors read and approved final version of the manuscript.

\section{Ethics approval and consent to participate}

The ethical approval was obtained from the Pharmacy Research Ethics Committee (PREC) at Akhtar Saeed College of Pharmaceutical Sciences (Reference: 14-2016/PREC, December 25, 2016). Before conducting the study, permission was granted from the hospital and pharmacy administrators. The purpose and protocols of this study were thoroughly explained to every participant and their verbal consents were obtained. Written consent was not possible for most of the respondents either because they were illiterate or they had problems in reading and/or signing the consent document. The PREC committee approved this consent procedure.

\section{Consent for publication}

Not applicable

\section{Competing interests}

The authors declare that they have no competing interests.

\section{Publisher's Note}

Springer Nature remains neutral with regard to jurisdictional claims in published maps and institutional affiliations.
Received: 10 August 2017 Accepted: 22 December 2017

Published online: 03 January 2018

\section{References}

1. Albreht T, et al. Making progress against cancer in Europe in 2008. Eur J Cancer. 2008;44(10):1451-6.

2. Shahid Mahmood, et al., Annual cancer registry report-2016, of the Shaukat Khanum Memorial Cancer Hospital \& Research Center, PAKISTAN. 2016: Pakistan.

3. Kantarjian HM, et al. Cancer drugs in the United States: Justum Pretium — the just price. J Clin Onco. 2013;31(28):3600-4.

4. Hillner BE, Smith TJ. Efficacy does not necessarily translate to cost effectiveness: a case study in the challenges associated with $21 \mathrm{st}-$ century cancer drug pricing. Proc Am Soc Clin Oncol. 2009;

5. Bhurgri $Y$, et al. Pakistan-country profile of cancer and cancer control 19952004. J Pak Med Assoc. 2006;56(3):124.

6. Nishtar DS. National Action Plan for prevention and control of noncommunicable diseases and. Health Promotion. 2004:162.

7. Azhar Qureshi, Burhan Ahmed Khan, and Qasim Mahmood, Overview: National Cancer Control Plan (Pakistan). 2006.

8. Cheema PK, et al. International variability in the reimbursement of cancer drugs by publically funded drug programs. Curr Oncol. 2012;19(3):e165-76.

9. Bigdeli $\mathrm{M}$, et al. Access to medicines from a health system perspective. Health Policy Plan. 2013;28(7):692-704.

10. Vogler S, Zimmermann N, Habl C. Understanding the components of pharmaceutical expenditure-overview of pharmaceutical policies influencing expenditure across European countries. GaBi J. 2013;2(3):178-87.

11. Howard DH, et al. Pricing in the market for anticancer drugs. J Econ Perspect. 2015;29(1):139-62.

12. Zaidi $\mathrm{S}$, et al. Access to essential medicines in Pakistan: policy and health systems research concerns. PLoS One. 2013;8(5):e63515.

13. Atif, M., et al., Pharmaceutical Policy in Pakistan, in Pharmaceutical Policy in Countries with Developing Healthcare Systems. 2017, Springer. p. 25-44.

14. Haider, M., Half of Pakistan population lives in poverty: UN report. The news, 2014.

15. Jamshed, S.Q., et al., The pharmaceutical industry, intellectual property rights and access to medicines in Pakistan, in The New Political Economy of Pharmaceuticals. 2013, Springer. p. 167-184.

16. Prasad V, De Jesus K, Mailankody S. The high price of anticancer drugs: origins, implications, barriers, solutions. Nat Rev Clin Oncol. 2017;14(6):381-90.

17. Mendis S, et al. The availability and affordability of selected essential medicines for chronic diseases in six low- and middle-income countries. Bull World Health Organ. 2007;85(4):279-88.

18. World Health Organization, Price, availability and affordability: an international comparison of chronic disease medicines. 2006.

19. Cherny N, et al. ESMO European consortium study on the availability, outof-pocket costs and accessibility of antineoplastic medicines in Europe. Ann Oncol. 2016;27(8):1423-43.

20. Government of the Punjab. Bureau of Statistics Punjab 2015.

21. Raosoft. Sample size calculator. 2015 [cited 2016 December 2015]; Available from: http://www.raosoft.com/samplesize.html.

22. Fedral Board of Revenue. Tax Payer Online Verification. Available from: https://e.fbr.gov.pk/registration/onlinesearchtaxpayer.aspx.

23. Neeshat, M., PharmaGuide, ed. M.Q. Neeshat. 2016, Karachi, Pakistan.

24. Khatib R, et al. Availability and affordability of cardiovascular disease medicines and their effect on use in high-income, middle-income, and low-income countries: an analysis of the PURE study data. Lancet. 2016;387(10013):61-9.

25. Jamshed A, et al. Improving cancer care in Pakistan. South Asian J Cancer. 2013;2(1):36-7.

26. Irfan SM, ljaz A, Shahbaz S. An assessment of service quality of private hospitals in Pakistan: a patient perspective. Indian Journal of Commerce and Management Studies. 2011;2(2):20-32.

27. Bhurgri $Y$, et al. Cancer incidence in Karachi, Pakistan: first results from Karachi cancer registry. Int J Cancer. 2000;85(3):325-9.

28. Cameron A, et al. Medicine prices, availability, and affordability in 36 developing and middle-income countries: a secondary analysis. Lancet. 2009:373(9659):240-9.

29. Yohana E, Kamuhabwa A, Mujinja P. Availability and affordability of anticancer medicines at the ocean road cancer Institute in Dar es salaam. Tanzania East Afr J Public Health. 2011:8(1):52-7. 
30. Kolasani BP, Malathi DC, Ponnaluri RR. Variation of cost among anti-cancer drugs available in Indian market. Journal of clinical and diagnostic research: JCDR. 2016;10(11):FC17.

31. Irfan SM, ljaz A, Shahbaz S. An assessment of service quality of private hospitals in Pakistan: a patient perspective. Ind J Commerce \& Management Studies. 2011;2(2):20-32.

32. Milani, B., W. Scholten, and W.H. Organization, The world medicines situation 2011: Access to controlled medicines 2011.

33. Farmer $\mathrm{P}$, et al. Expansion of cancer care and control in countries of low and middle income: a call to action. Lancet. 2010;376(9747):1186-93.

34. Gota VS, Patial P. Toward better quality of anticancer generics in India. Indian J Cancer. 2014;51(3):366-8.

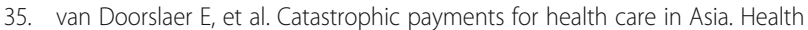
Econ. 2007;16(11):1159-84.

36. Ministry of Health Government of Pakistan and World Health Organization, Pharmaceutical Country Profile for Pakistan. 2010.

\section{Submit your next manuscript to BioMed Central} and we will help you at every step:

- We accept pre-submission inquiries

- Our selector tool helps you to find the most relevant journal

- We provide round the clock customer support

- Convenient online submission

- Thorough peer review

- Inclusion in PubMed and all major indexing services

- Maximum visibility for your research

Submit your manuscript at www.biomedcentral.com/submit 